\title{
Avaliação da mancha preta dos citros em diferentes variedades de laranjeira doce
}

\author{
Marcos Paulo Rossetto ('); Fernando Alves de Azevedo (2*); Ivan Bortolato Martelli ('); \\ Evandro Henrique Schinor ( $\left.{ }^{1}\right)$ \\ (1) Instituto Agronômico (IAC), Pós-graduação em Agricultura Tropical e Subtropical, Caixa Postal 28, 13012-970 Campinas (SP). \\ (2) Instituto Agronômico (IAC), Centro Avançado de Pesquisa Tecnológica do Agronegócio de Citros Sylvio Moreira, Caixa Postal 04, \\ 13490-970 Cordeirópolis, (SP). E-mail: fernando@centrodecitricultura.br (*) Autor correspondente.
}

Recebido: 16/abr./2010; Aceito: 18/mai./2010

\section{Resumo}

A mancha preta dos citros (MPC), causada por Guignardia citricarpa Kiely, tem sido responsável por grandes prejuízos no Brasil, onde todas as variedades comerciais de laranjeira doce são suscetíveis. Tendo em vista as perdas econômicas que essa doença causa à citricultura brasileira, este trabalho teve como objetivo avaliar variedades de laranjeiras de maturação tardia quanto à suscetibilidade à MPC. Trinta e seis variedades foram avaliadas em dois anos (2007 e 2008), em Cordeirópolis (SP), e 35 em Conchal (SP), em experimentos utilizando-se delineamento de blocos casualizados, com três repetições. A severidade da MPC foi quantificada, entre os meses de junho a novembro (2007 e 2008), utilizando-se escala diagramática e, posteriormente, calculou-se a área abaixo da curva do progresso da doença. Todas as variedades foram suscetíveis à MPC, entretanto a Imperial e a Valência Pálida Israel mostraram menor suscetibilidade nos dois campos experimentais.

Palavras-chave: Guignardia citricarpa, Citrus sinensis, variedade copa.

\section{Evaluation of citrus black spot in diferent varieties of sweet orange}

\begin{abstract}
The citrus black spot - CBS (Guignardia citricarpa Kiely) has been responsible for great losses in Brazil, where all commercial varieties of sweet orange are susceptible. Given the economic losses that this disease causes to the brazilian citrus industry, this study aimed to evaluate the susceptibility of sweet orange varieties with late harvest to CBS. A total of 36 varieties were evaluated in Cordeirópolis city, and 35 located at Conchal city, in two years (2007 and 2008), both in São Paulo State, Brazil, in randomized block design assays with three replications. By using a diagrammatic scale specific to the CBS, the severity of CBS was quantified between the months from June to November (2007 and 2008), data was used to calculate the area under disease progress curve. All varieties were susceptible to CBS, however Imperial and Valência Pálida Israel were less susceptible than the others at both locations.
\end{abstract}

Key words: Guignardia citricarpa, Citrus sinensis, scion variety.

\section{INTRODUÇÃO}

O Brasil é o maior produtor de citros do mundo, e assim, a citricultura ocupa lugar de destaque no país, devido ao seu grande valor de exportação e à sua importância social, gerando grande número de empregos e permitindo que pequenos proprietários permaneçam com suas famílias sobrevivendo no campo.

Em 2008, o valor total das exportaçôes brasileiras de suco de laranja industrializado (concentrados, congelados e outros) atingiu US\$ 2,0 bilhóes (SECEX/Mdic, 2009) e o país produziu 457,7 milhóes de caixas de laranja $(40,8$ $\mathrm{kg}$ ); São Paulo, maior estado produtor, respondeu por 79\% (360,0 milhōes de caixas) desse total (IвGE, 2009).

$\mathrm{Na}$ citricultura, além das questôes econômicas e de mercado, os produtores enfrentam sérios problemas fitossanitários, o que tem acometido os pomares brasileiros, principalmente do Estado de São Paulo, onde a ocorrência de doenças é favorecida pela presença de tecidos foliares sempre verdes e clima adequado, o que permite a continuidade do ciclo de várias doenças.

Dentre as principais doenças da cultura, destaca-se a mancha preta dos citros (MPC), causada pelo fungo Guignardia citricarpa Kiely. Essa doença é responsável por grandes prejuízos em várias regiōes produtoras de citros do mundo como Austrália e África do Sul, e mais recentemente nas regiôes produtoras brasileiras. Todas as principais variedades copas comerciais presentes nos pomares paulistas são suscetíveis, exceto a laranjeira azeda (Citrus aurantium. L.) e a limeira ácida Tahiti (Citrus latifolia Osbeck) (KotzÉ, 1981). Por isso, a MPC pode ser considerada, atualmente, a principal doença fúngica afetando as laranjeiras doces. 
No Estado de São Paulo, a MPC foi detectada pela primeira vez em 1992, em plantas de limoeiros verdadeiros e laranjeiras doces de maturação tardia nos municípios de Conchal e Engenheiro Coelho, (Goes e Feichtenberger, 1993). Atualmente, a doença já está presente em diversas regiôes da citricultura paulista. Embora tenha sido confirmada em quase vinte municípios na década de 90, AguiLAR-VILDOSo (1997) relatou naquela época que o número deveria ser superior por três motivos: falta de envio de material suspeito, a não-presença de sintomas em plantas novas, mudas e borbulhas e o menor progresso da doença.

Para as condições brasileiras, a ocorrência da doença pode ter início tanto em picnidiósporos (conídios) presentes em picnídios formados nas lesōes existentes nos frutos maduros, ramos e folhas caídas no solo, como nos ascósporos, formados em folhas em decomposição caídas no solo sob as plantas cítricas (Laranjeira et al., 2005; Goes, 1998). Os picnidiósporos constituem importante fonte adicional de inóculo do patógeno, em relação a outros países como Austrália e África do Sul, onde a doença está presente (Feichtenberger et al., 2005; Laranjeira et al., 2005).

O controle da MPC está fundamentado na utilização de fungicidas protetores e sistêmicos usados separadamente ou em conjunto, associados ou não a óleo mineral/vegetal. No Brasil, o controle é realizado com base em informaçóes geradas em outros países, especialmente da África do Sul, onde a doença também é de importância relevante (Goes, 2002). Atualmente, no Brasil, a MPC vem sendo manejada, principalmente, através do controle químico sistemático, e inúmeras pulverizações com fungicidas específicos são realizadas (4-5 aplicaçôes/ano). Por isso, fica evidente a necessidade de se obter novas alternativas de controle que possam colaborar com o sistema de produção atual.

Tendo em vista as consideraçóes acima mencionadas, as perdas econômicas que a MPC causa e sabendo-se das diferenças de suscetibilidade entre as espécies e variedades cítricas, é de grande importância a caracterização da resistência dentro do gênero Citrus. Poucos trabalhos avaliando variedades de laranjeiras quanto à suscetibilidade à MPC são encontrados na literatura. Porém, destaca-se o estudo de Schinor et al. (2002), que avaliou variedades do grupo das laranjeiras Pêra e afins.

Dessa forma, o objetivo deste trabalho foi avaliar diferentes variedades de laranjeiras de maturação tardia quanto à suscetibilidade à mancha preta dos citros nos municípios de Cordeirópolis e Conchal, no Estado de São Paulo.

\section{MATERIAL E MÉTODOS}

\section{Local e material vegetal estudado}

As avaliaçôes da mancha preta dos citros foram realizadas em dois locais (experimentos): a) Cordeirópolis (SP) - experimento 1 - no Banco Ativo de Germoplasma de Citros (BAG-Citros), localizado a $22^{\circ} 32^{\prime}$ de latitude $S$ e $47^{\circ} 27^{\prime}$ de longitude W; com altitude de $639 \mathrm{~m}$; clima do tipo Cwa, pela classificação de Koppen (Ortolani et al., 1991). O solo é da classe Latossolo Vermelho distrófico típico (Embrapa, 1999). As plantas do BAG-Citros têm 20 anos e foram implantadas em espaçamento de 7,5 m entre linhas x 3,0 m entre plantas, enxertadas em tangerina Cleópatra (Citrus reshni hort. Ex Tanaka). Selecionaram-se 36 diferentes copas para as avaliaçôes, prevalecendo as de maturação tardia.

b) Conchal (SP) - experimento 2 - situado sob coordenadas geográficas de $22^{\circ} 25^{\prime}$ latitude $S$ e $47^{\circ} 09^{\prime}$ longitude W. O pomar possui 644 plantas, implantadas em 1997 (12 anos) em espaçamento de 6,0 m entre linhas x 3,0 m entre plantas, onde as variedades estudadas também estão enxertadas em tangerina Cleópatra. Esse experimento de laranjeira de maturação tardia é de responsabilidade do pesquisador Dr. José Orlando Figueiredo, do Centro de Citros Sylvio Moreira/IAC, contando com 48 diferentes copas, onde um total de 35 variedades foi selecionado para avaliação.

Os dois experimentos foram instalados em delineamento de blocos ao acaso com três repetiçóes, sendo cada parcela composta por uma planta de cada variedade.

\section{Avaliação da severidade da mancha preta dos citros}

Um total de 40 frutos por repetição (planta) foi avaliado quanto à suscetibilidade à mancha preta dos citros, utilizando-se escala diagramática de notas, elaborada por Aguilar-Vildoso et al. (2002), a qual é composta por seis níveis de severidade (Figura 1).

Em 2007, quatro avaliaçóes foram realizadas em Cordeirópolis, SP (29/mai, 14/jul, 13/ago e 09/set) e três em Conchal, SP (31/jul, 22/ago e 05/set). Em 2008, as avaliaçôes no experimento 1 foram realizadas em $13 /$ jul, 08/ago, 12 /set e $15 /$ out e no experimento 2 , em 11 /jun, 26/ago, 15/out e 19/nov.

Os valores de severidade, em porcentagem, foram utilizados para calcular a área abaixo da curva do progresso da doença (AACPD) pelo método da integração trapezoidal (Shaner e Finney, I977) e esses dados foram submetidos à análise de variância, e posteriormente, comparados estatisticamente pelo teste de Scott-Knott ( $\mathrm{P}$ $>0,05 \%$ ), utilizando-se o software SASM-Agri - Sistema para Análise e Separação de Médias em Experimentação Agrícola (Althaus et al., 2001). 


\section{Pulverizações realizadas}

No experimento 1, as pulverizaçóes para controlar a MPC foram realizadas com turbo atomizador tratorizado da marca Jacto, modelo Arbus 2000, calibrado em $130 \mathrm{~b} \mathrm{pol}^{-2}$, com velocidade de trabalho de $4 \mathrm{~km} \mathrm{~h}^{-1}$. Todas as pulverizaçôes tiveram a adição de $0,5 \%$ de óleo mineral. Já no experimento 2, as pulverizaçóes foram realizadas com turbo atomizador tratorizado da marca $\mathrm{KO}$, com capacidade para $2000 \mathrm{~L}$, calibrado em $200 \mathrm{lb} \mathrm{pol}^{-2}$ com velocidade de trabalho de $4 \mathrm{~km} \mathrm{~h}^{-1}$. Em todas as pulverizaçóes, adicionou-se 0,25\% de óleo mineral. O número e a data das aplicaçôes, ingredientes ativos utilizados e dosagem para as duas localidades e safras podem ser observados na tabela 1 .

\section{RESULTADOS E DISCUSSÃO}

Nos dois experimentos, em Cordeirópolis (SP) e Conchal (SP), observaram-se diferenças estatísticas entre as variedades para a AACPD, nos dois ciclos de avaliaçóes - 2007 e 2008 (Tabelas 2 e 3).

No experimento 1- Cordeirópolis (SP) - a variedade Vaccaro destacou-se, com AACPD de 8,96 e 11,76 nas avaliaçôes realizadas em 2007 e 2008, respectivamente, seguida por Pingo de Ouro $(35,72$ e 16,31) e Corsa Tardia $(56,40$ e 23,73), como as mais resistentes à Guignardia citricarpa.

No segundo ano de avaliação (2007), dentre as variedades mais suscetíveis, destaca-se a Natal cv. África do Sul com maior valor para AACPD $(319,17)$ dentro do grupo avaliado. Outras variedades, comercialmente cultivadas, como Natal e Natal Murcha também tiveram maior suscetibilidade, com valores de, respectivamente, 101,34 e 152,98 para a AACPD (Tabela 2).

Há relatos na literatura em que a variedade Natal também possui suscetibilidade a outras doenças como a leprose dos citros (Maia e Oliveira, 2005), enquanto que a Folha Murcha é mais suscetível à clorose variegada dos citros (Franco et al., 2008). No caso específico da MPC, BALDASSARI (2001) demonstrou que as variedades Valência e Natal, de maturação tardia, são suscetíveis; Goes et al. (1990) relataram suscetibilidade das variedades de laranjeira doce Lima, Folha Murcha, Natal, Pêra e Valência, e também suscetíveis nas avaliaçôes realizadas no presente estudo.

No experimento 2 - Conchal (SP) - a variedade Berna proporcionou AACPD de 141,88 e 179,00, em 2007 e

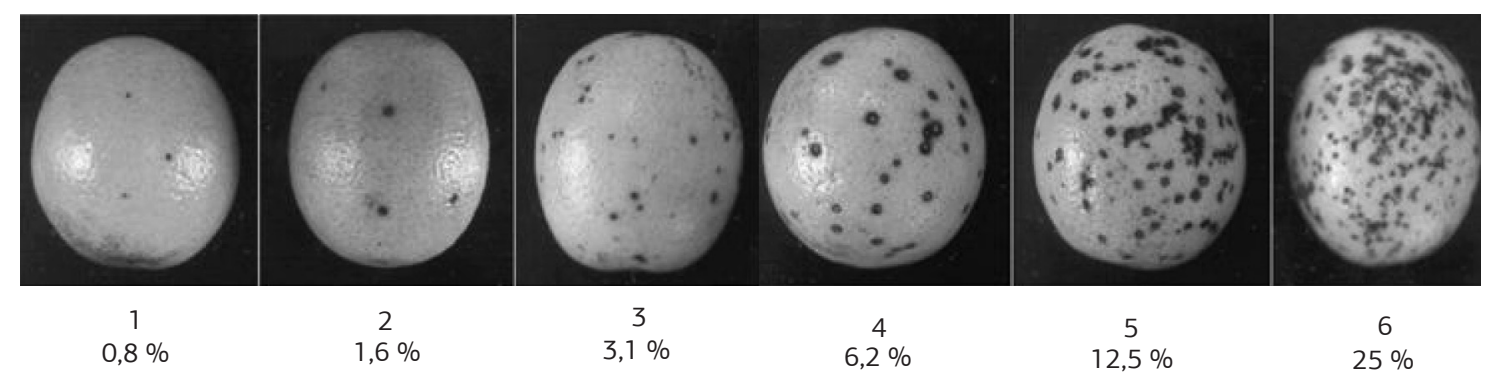

Figura 1. Escala de notas para avaliação da severidade da mancha preta dos citros. Fotos: Aguillar-Vildoso et al. (2002).

Tabela 1. Número e data das aplicaçóes, ingrediente ativo (ia) utilizado e dosagem para o controle da mancha preta dos citros nos municípios paulista de Cordeirópolis (SP) e Conchal (SP) nas safras 2006/2007 e 2007/2008

\begin{tabular}{|c|c|c|}
\hline Número e data das aplicações & Ingrediente ativo & Dosagem \\
\hline Cordeirópolis & \multicolumn{2}{|c|}{ g $100 \mathrm{~L}^{-1}$ de i.a. Safra 2006/2007 } \\
\hline $1^{a}-22 / 9 / 06$ & Tiofanato metílico & 35 \\
\hline $2^{a}-24 / 10 / 06$ & Oxicloreto de cobre & 174 \\
\hline \multirow[t]{2}{*}{$3^{a}-24 / 1 / 07$} & Carbendazim & 25 \\
\hline & \multicolumn{2}{|c|}{ Safra $2007 / 2008$} \\
\hline $1^{a}-07 / 11 / 07$ & Mancozeb + carbendazim & $44,5+25$ \\
\hline $2^{a}-20 / 12 / 07$ & Propinebe + trifloxistrobina & $70+7,5$ \\
\hline $3^{a}-24 / 1 / 07$ & Carbendazim & 25 \\
\hline $4^{a}-3 / 3 / 08$ & Oxicloreto de cobre & 174 \\
\hline Conchal & & \\
\hline $1^{a}-10 / 10 / 06$ & Hidróxido de cobre & 85,5 \\
\hline $2^{a}-16 / 11 / 06$ & Carbendazim & 25 \\
\hline \multirow[t]{2}{*}{$3^{a}-22 / 12 / 06$} & Carbendazim & 25 \\
\hline & \multicolumn{2}{|c|}{ Safra $2007 / 2008$} \\
\hline $1^{a}-10 / 11 / 07$ & Hidróxido de cobre & 85,5 \\
\hline $2^{a}-25 / 12 / 07$ & Carbendazim & 25 \\
\hline $3^{a}-5 / 2 / 08$ & Oxicloreto de cobre & 174 \\
\hline
\end{tabular}


Tabela 2. Área abaixo da curva do progresso da doença (AACPD) em variedades de laranjeira doce obtidas do Banco Ativo de Germoplasma de Citros (Centro de Citros Sylvio Moreira/IAC), Cordeirópolis (SP), nas safras 2006/2007 e 2007/2008

\begin{tabular}{|c|c|c|}
\hline \multirow{2}{*}{ Variedades ( $n .^{\circ}$ variedade no BAG - nome) } & \multicolumn{2}{|c|}{ AACPD } \\
\hline & 2007 & 2008 \\
\hline 481 - Natal cv. Africa do Sul & $319,17 a^{*}$ & $92,22 b$ \\
\hline 490 - Natal Murcha & $152,98 b$ & $52,80 c$ \\
\hline 473 - Murcha cv. Faz. Ipitangas & $145,75 b$ & $84,57 b$ \\
\hline 491 - Natal Murcha 2 & $131,17 b$ & $46,87 c$ \\
\hline 487 - Natal Murcha 3 & $129,69 b$ & $65,21 c$ \\
\hline 479 - Valência Campbell Bahia & $122,01 b$ & $25,98 d$ \\
\hline 472 - Murcha Faz. Ipitangas & $118,64 b$ & $66,08 c$ \\
\hline 484 - Pera Pirangi & $106,79 b$ & $88,14 b$ \\
\hline 489 - Valência Murcha Severinia SP & $105,90 b$ & $78,81 \mathrm{c}$ \\
\hline 188 - Natal & $101,34 b$ & $47,06 c$ \\
\hline 477 - Valência cv. EEPRS & $104,16 b$ & $57,13 c$ \\
\hline 474 - Murcha cv. Faz. Ipitangas & $93,21 c$ & $84,57 b$ \\
\hline 174 - Lambsummer & $75,62 c$ & $140,81 a$ \\
\hline 190 - Valência Late & $66,09 c$ & $50,10 c$ \\
\hline 475 - Valência & $59,74 c$ & $35,89 d$ \\
\hline 138 - Sangüinea & $59,58 c$ & $75,37 c$ \\
\hline 191 - Lue Gin Gong & $58,46 c$ & $38,40 d$ \\
\hline 85 - Corsa Tardia & $56,40 c$ & $23,73 d$ \\
\hline 196 - Pele de Moça & $54,87 c$ & $87,16 b$ \\
\hline 99 - Ouro & $53,32 c$ & $24,06 d$ \\
\hline 151 - Imperial & $53,23 c$ & $31,50 d$ \\
\hline 470 - Blood Oval cv. & $48,54 c$ & $26,48 d$ \\
\hline 197 - Diva & $48,10 c$ & $44,94 \mathrm{c}$ \\
\hline 170 - Setúbal & $46,10 c$ & $64,82 c$ \\
\hline 176 - Pera Caire & $43,71 c$ & $81,86 b$ \\
\hline 415 - Lima Verde & $41,08 c$ & $57,95 c$ \\
\hline 193 - Hart`s Late & $40,75 c$ & $52,80 \mathrm{c}$ \\
\hline 178 - Pera Coroada & $40,53 c$ & $76,14 c$ \\
\hline 89 - Coco & $39,73 c$ & $120,52 a$ \\
\hline 184 - Valência Palida Israel & $39,46 c$ & $34,98 d$ \\
\hline 448 - Verna & $39,11 c$ & $32,04 d$ \\
\hline 105 - Pingo de ouro & $35,72 c$ & $16,31 d$ \\
\hline 430 - Sanguinelli & $34,02 c$ & $23,73 d$ \\
\hline 471 - Navel Sangri cv. Dieberger & $27,73 c$ & $32,22 d$ \\
\hline 171 - Ovale de Siracusa & $19,46 c$ & $67,92 c$ \\
\hline 79 - Vaccaro & $8,96 d$ & $11,76 d$ \\
\hline Coeficiente de variação & 37,99 & 17,07 \\
\hline
\end{tabular}

Médias seguidas da mesma letra em cada coluna nẫo diferem entre si (Scott-Knott 5\%).

2008, respectivamente, enquanto Setúbal (AACPD de 26,49 e 19,90), Valência Pálida Israel (AACPD de 29,18 e 33,38) e Imperial (AACPD de 55,37 e 17,95) revelaram menores valores nos dois anos de avaliação (Tabela 3).

De maneira geral, destaca-se que nas variedades Imperial e Valência Pálida Israel havia menor suscetibilidade à MPC em 2008, nos dois experimentos. Outro fato relevante é que menores valores de AACPD foram observados em Conchal (SP), nos dois anos, porém, dentro do grupo de variedades avaliadas, também não se observou resistência à MPC, como relatado por outros autores (AlcoBA et al., 2000; Aguilar-Vildoso et al., 2002; Góes, 2002).

A suscetibilidade do grupo das laranjeiras doces também é relatada por Spósito et al. (2004), que avaliaram as variedades comerciais Hamlin, Pêra e Valência e por Schinor et al. (2002) analisando seleçôes do grupo das chamadas Pêra. Aguilar-Vildoso et al. (2002) ainda descreveram que a MPC afeta todas as variedades comerciais de laranjeiras doces cultivadas no País.

Nas primeiras avaliaçóes de campo (maio - junho), em ambas as localidades, foram observados menores valores de severidade (dados não demonstrados), o que também foi relatado por FeICHTENBERger (1996) para essa mesma época (frutos verdes). Com a maturação dos frutos, altas temperaturas e intensa radiação solar, condiçôes ambientais que favorecem a expressão dos sintomas da MPC (KотZÉ, 1963), foram observados incrementos nos valores de severidade.

Em 2008, observou-se aumento da severidade da MPC na última avaliação das plantas do experimento 2, o que pode ter ocorrido devido ao controle químico 
Tabela 3. Área abaixo da curva do progresso da doença (AACPD) em variedades de laranjeira doce obtidas da Fazenda Piraporinha, Conchal (SP), nas safras 2006/2007 e 2007/2008

\begin{tabular}{|c|c|c|}
\hline \multirow{2}{*}{ Variedades ( $n .^{\circ}$ variedade no experimento - nome) } & \multicolumn{2}{|c|}{ AACPD } \\
\hline & 2007 & 2007 \\
\hline 36 - Berna & $141,88 a$ & $179,00 a$ \\
\hline 25 - Pingo de Ouro & $80,08 b$ & $30,37 b$ \\
\hline 24 - Pera Caire & $88,74 b$ & $42,49 b$ \\
\hline 31 - Natal & $72,58 c$ & $61,35 b$ \\
\hline $42-$ Coco & $65,18 c$ & $42,58 b$ \\
\hline 19 - Lue Gin Gong & $58,05 c$ & $57,75 b$ \\
\hline 37 - Pêra Premunizada & $56,54 c$ & $66,48 b$ \\
\hline 23 - Imperial & $55,37 c$ & $17,95 b$ \\
\hline 12 - Artebanta & $54,29 c$ & $48,71 b$ \\
\hline 16 - Valência & $53,62 c$ & $48,80 b$ \\
\hline 4 - Valência Late & $53,57 c$ & $58,94 b$ \\
\hline 6 - Folha Murcha & $52,42 c$ & $135,35 a$ \\
\hline 35 - Natal & $51,97 c$ & $26,44 b$ \\
\hline 39 - Tobias & $51,61 c$ & $32,68 b$ \\
\hline 15 - Valência Betti & $50,99 c$ & $52,04 b$ \\
\hline 30 - Citrus Sinensis & $50,64 c$ & $39,32 b$ \\
\hline 22 - Pele de Moça & $50,24 c$ & $27,43 b$ \\
\hline 34 - Valência & $48,99 c$ & $36,83 b$ \\
\hline 3 - Berry Valência & $48,22 c$ & $62,19 b$ \\
\hline 47 - São Miguel & $46,20 c$ & $43,90 b$ \\
\hline 11 - Ibicaba & $44,58 c$ & $55,81 b$ \\
\hline 13 - Hart's Late & $43,80 c$ & $46,25 b$ \\
\hline 27 - Whit's Late Valência & $43,42 c$ & $49,27 b$ \\
\hline 45 - Valência Campbell & $40,48 d$ & $38,52 b$ \\
\hline 48 - Natal Murcha & $39,33 d$ & $49,36 b$ \\
\hline 28 - Strand & $38,13 d$ & $35,38 b$ \\
\hline 20 - Werley Valencia & $35,01 d$ & $49,27 b$ \\
\hline 40 - Valência Tuxpan & $34,08 d$ & $29,30 a$ \\
\hline 14 - Natal Bebedouro & $32,16 d$ & $64,51 b$ \\
\hline 8 - Ouro & $32,08 \mathrm{~d}$ & $40,97 b$ \\
\hline 38 - Valência Pálida Israel & $29,18 d$ & $33,38 b$ \\
\hline 29 - Chafeei Late Valência & $28,27 d$ & $63,27 b$ \\
\hline 46 - Valência Olinda & $26,77 d$ & $96,65 a$ \\
\hline 43 - Setúbal & $26,49 d$ & $19,90 b$ \\
\hline 41 - Hale & $23,77 d$ & $123,93 a$ \\
\hline Coeficiente de variação & 24,99 & 49,12 \\
\hline
\end{tabular}

Médias seguidas da mesma letra em cada coluna não diferem entre si (Scott-Knott 5\%).

realizado nessa safra, retardando o aparecimento dos sintomas (Tabela 1). Em Cordeirópolis, notaram-se maiores valores de AACPD em 2007, o que pode ser justificado pelo menor número de aplicaçóes de fungicidas nesse ano (Tabela 1).

Em dados obtidos por Schinor et al. (2002), em Cordeirópolis (SP) no Centro de Citros Sylvio Moreira) os valores de severidade e incidência de MPC, em 1999 e 2000, foram inferiores aos obtidos neste trabalho. Ressalta-se que os resultados obtidos pelos autores foram observados em pomar sem aplicaçóes de fungicidas para o controle da doença, demonstrando, dessa forma, aumento na severidade da MPC atualmente, uma vez que valores superiores foram observados no presente trabalho, no mesmo local, mesmo com a aplicação de fungicidas.
Atualmente, há na citricultura brasileira problemas fitossanitários graves como o huanglongbing (ou greening), doença que coloca em risco a viabilidade do agronegócio citrícola. Assim, para o citricultor dispor de uma variedade resistente à determinada doença, resultaria concomitantemente em menor custo de produção e, consequentemente maior lucro. Com isso é de extrema importância a continuidade dos trabalhos com melhoramento de citros visando à obtenção de variedades resistentes às principais doenças da cultura. Dessa forma, apesar dos resultados observados neste estudo mostrarem que não há variedades resistentes à MPC, algumas são menos suscetíveis (Vaccaro, Imperial e Valência Pálida Israel) e podem, em futuro próximo, tornar-se novas opçóes de variedades ao citricultor brasileiro. 


\section{CONCLUSÃO}

Todas as variedades são suscetíveis à mancha preta dos citros, dentre as variedades comuns nos dois experimentos, porém as variedades Imperial e a Valência Pálida Israel são as de menor suscetibilidade.

\section{AGRADECIMENTOS}

Os autores agradecem ao Conselho Nacional de Desenvolvimento Tecnológico e Científico (CNPq) e ao Fundo de Defesa da Citricultura (Fundecitrus) pelo apoio financeiro ao projeto e pela concessão da bolsa de mestrado ao primeiro autor.

\section{REFERÊNCIAS}

AGUILAR-VILDOSO, C.I. Pinta preta espalha-se por São Paulo. Citricultura Atual, v.1, p.8, 1997.

AGUILAR-VILDOSO, C.I.; RIBEIRO, J.G.B.; FEICHTENBERGER, E.; GÓES, A. de; SPÓSITO, M.B. Manual Técnico de Procedimentos da Mancha Preta dos Citros. Brasília: MAPA/DAS/DDIV, 2002. 72p.

ALCOBA, N.J.; VIGIANI, A.R.; BEJARANO, N.V.; ALVAREZ, S.E.; SERRANO, M.A.; BONILLO, M.C. Mancha negra de los cítricos epidemiologia y control. Jujuy: Universidad Nacional de Jujuy, 2000. 56p.

ALTHAUS, R.A., CANTERI, M.G.; GIGLIOTI, E.A. Tecnologia da informação plicada ao agronegócio e ciências ambientais: sistema para análise e separação e médias pelos métodos de Duncan, Tukey e Scott-Knott. In: Encontro Anual de Iniciação Científica, 10. 2001, Ponta Grossa. Anais... Ponta Grossa: UEPG, 2001.

BALDASSARI, R.B. Influência de frutos sintomáticos de uma safra na incidência da Guignardia citricarpa na safra subsequente e período de suscetibilidade de frutos de laranjeiras Natal e Valência. 2001. 72p. Dissertação (Mestrado). Faculdade de Ciências Agrárias e Veterinárias, Universidade Estadual Paulista, Jaboticabal.

EMBRAPA Centro Nacional de Pesquisas de solos (Rio de Janeiro, RJ). Sistema Brasileiro de classificação de solos. Brasília: Embrapa Produção de Informação; Rio de Janeiro: Embrapa Solos, 1999. $412 \mathrm{p}$.

FEICHTENBERGER, E. Mancha-preta dos citros no Estado de São Paulo. Laranja, v.17, p.79-92, 1996.

FEICHTENBERGER, E.; MULLER, G.W.; GUIRADO, N. Doenças dos citros. In: KIMATI, H.; AMORIN, L.; BERGAMIN FILHO, A.; CAMARGO, L.E.A.; REZENDE, J.A.M. (Eds.). Manual de Fitopatologia. São Paulo: Agronômica Ceres, p.239$269,2005$.

FRANCO, D.; MARTINS, A.B.G.; STUCHI, E.S.; SILVA, S.R.da; LARANJEIRA, F.R. Danos as plantas e produção de seis cultivares de laranjeiras doces sob infecção natural de Xylella fastidiosa. In:
CONGRESSO BRASILEIRO DE FRUTICULTURA, 20, 2008, Vitória. Anais... Vitória: INCAPER, 2008. (CD ROM)

GOES, A. Controle da Mancha-preta dos frutos cítricos. Laranja, v.19, p.305-320, 1998.

GOES, A. Efeito da combinação de fungicidas sistêmicos e protetores no controle da mancha preta dos frutos cítricos causada por Guignardia citricarpa. Summa Phytopathologica, v.28, p.09-13, 2002.

GOES, A.; FEICHTENBERGER, E. Ocorrência da Mancha Preta causada por Phyllosticta citricarpa (Mc Alp) Van der Aa (Guignardia citricarpa Kiely) em pomares cítricos do Estado de São Paulo. Fitopatologia Brasileira, v.18, p.318, 1993.

GOES, A.; GRAÇA, J.; BARROS, J.C.S.M.; PINHEIRO, J.E. Controle de pinta preta em frutos de tangerina Rio (Citrus deliciosa), ocasionada por Phyllosticta citricarpa (Guignardia citricarpa Kiely). Fitopatologia Brasileira, v.15, p.73-75, 1990.

IBGE - Instituto Brasileiro de Geografia e Estatística. 2009. Disponível em http://www.ibge.gov.br. Acesso em 20 fev. 2009.

KOTZÉ, J.M. Epidemiology and control of citrus black spot in South Africa. Plant Disease, v.65, p.945-950, 1981.

KOTZÉ, J.M. Studies on the black spot disease of citrus caused by Guignardia citricarpa Kiely, with particular reference to its epiphytology and control at Labata. Pretoria, 1963. 143p. Tese (Doutorado) - University of Pretoria.

LARANJEIRA, F.F.; FEICHTENBERGER, E.; BASSANEZI, R.B.; SPÓSITO, M.B. Manejo integrado de doenças dos citros. In: MATTOS JR., D.; DE NEGRI, J.D.; PIO, R.M.; POMPEU JR, J. (Ed.). Citros. Campinas: Instituto Agronômico e Fundag, 2005. p.631-652.

MAIA, O.M.A.; OLIVEIRA, C.A.L. Transmissibilidade do vírus da leprose de cercas vivas, quebra-ventos e plantas daninhas para laranjeiras através de Brevipalpus Phoenicis Geijskes. Bragantia, v.64, p. 417-422, 2005.

ORTOLANI, A.A.; PEDRO JÚNIOR, M.J.; ALFONSI, R.R. Agroclimatologia e cultivos dos citros. In: RODRIGUEZ, O.; VIEGAS, F.; POMPEU JÚNIOR, J.; AMARO, A.A. (Coord.) Citricultura Brasileira. Campinas: Fundação Cargill, 1991. p.153-194.

SCHINOR, E.H.; MOURÃO FILHO F.A.A.; AGUILARVILDOSO C.I.; TEÓFILO SOBRINHO J. Incidência e severidade da mancha preta dos citros em seleções de laranjeira 'Pêra' e variedades afins. Laranja, v.23, p.387-400, 2002.

SECEX/MDIC - SECRETARIA DE COMÉRCIO EXTERIOR/ MINISTÉRIO DO DESENVOLVIMENTO, INDÚSTRIA E COMÉRCIO. 2009. Disponível em http://www.aliceweb. desenvolvimento.gov.br. Acesso em 20 fev. 2009.

SHANER, G.; FINNEY, R.E. The effect of nitrogen fertilization on the expression of slow-mildewing resistance in knox wheat. Phytopathology, v.70, p.1183-1186, 1977.

SPÓSITO, M.B., BASSANEZI, R.B.; AMORIM, L. Resistência à mancha preta dos citros avaliada por curvas de progresso da doença. Fitopatologia Brasileira, v.29, p.532-537, 2004. 